\title{
Photocatalytical Degradation of Congo Red Azo Dye Using Phosphono- Aminoacid-Cd(II) Pendant Groups Grafted on a Polymeric Support
}

\begin{abstract}
LAURA COCHECI ${ }^{1}$, LAVINIA LUPA ${ }^{1}$, ANIELA POP ${ }^{1}$, AURELIA VISA², BIANCA MARANESCU², ADRIANA POPA ${ }^{2 *}$
'Politehnica University of Timisoara, Faculty of Industrial Chemistry and Environmental Engineering,

6 Vasile Parvan Blvd., 300223, Timisoara, Romania

${ }^{2}$ Institute of Chemistry Coriolan Dragulescu 24 Mihai Viteazul Blvd., 300223 Timisoara, Romania

In the present study, a new compound was used for decontaminating water polluted by Congo Red dye. Phosphono-aminoacid-Cd(II) pendant groups grafted on a polymeric support was prepared using impregnation of a polymer support functionalized with phosphono-aminoacid groups with an aqueous solution of $\mathrm{Cd}\left(\mathrm{NO}_{3}\right)_{2} \times \mathrm{H}_{2} \mathrm{O}$. The catalyst was characterized by Fourier transform infrared ray, scanning electron microscope, termogravimetric analysis UV-Vis spectroscopy. The results suggest that the studied material could efficiently be used as photocatalyst in the degradation process of waters containing organic dyes under UV-Vis light irradiation.
\end{abstract}

Keywords: photocatalysts, Congo Red azo dye, phosphono-aminoacid-Cd(II) groups

Physical methods such as adsorption, biological methods (biodegradation) and chemical methods such as chlorination and ozonation are the most frequently used methods for removing the pollutants from wastewater [1]. Among these processes, the chemical method of photocatalytic degradation of different types of pollutants (such as dyes) in wastewaters under UV-Vis light irradiation is considered an efficient and important techniques [ 1,2$]$.

Dyes represent one of the largest groups of organic compounds. They have been widely used as additives and colorants in food, textiles, leather, papermaking, printing, ink, cosmetics, drugs and also in pharmaceutical industries. Environmental pollution resulting from organic pollutants such as textile dyes is a real danger $[3,4]$. Among the problematic dyes are the azo dyes, and of these, Congo Red (CR) is used extensively in textile industries $[5,6]$. The IUPAC name of CR dye is sodium salt of 3,3-([1,1-biphenyl]4,4-diyl) bis(4-aminonaphthalene-1-sulfonic acid) with a molecular weight of $696.66 \mathrm{~g} \mathrm{~mol}^{-1}[5,7]$.

Synthetic polymeric sorbents of diverse types are quite extensively used in the sorption of organic compounds from aqueous solutions. Chelating polymers are characterized by the presence of reactive functional groups containing $\mathrm{N}$ and $\mathrm{P}$ donor atoms. The adsorptive properties of such resins containing new á-hydroxyphosphonic acid groups were investigated [8]. For these adsorption studies three dyes were used as test such as: monoazoic dye Al (anthranilic acid - 2-amino-5-naphtol-7-sulfonic acid), monoazoic dye ABS ( $p$-aminobenzoic acid - salicylic acid), and anthraquinone dye ABA (bromaminic acid) [9]. Aliphatic and aromatic phosphonium salts grafted on a gel-types tyrene-7\%divinylbenzen copolymer were used as adsorbent materials for decontaminating colored wastewater [10]. Therefore the polymeric materials impregnated with the disazoic direct dye were used further in removal of $\mathrm{Cu}(\mathrm{II})$ ions and $\mathrm{Zn}(\mathrm{II})$ ions from aqueous solution [10].

In this study, a new compound for photocatalytic action was used for decontaminating water polluted by Congo Red dye. The complex of phosphono-aminoacid pendant groups grafted onto styrene-6.7\%divinylbenzene copolymer with Cd(II) was tested under UV-light for the removal of the dye from an aqueous solution.

\section{Experimental part}

Materials and methods

Cadmium nitrate $\left(\mathrm{Cd}\left(\mathrm{NO}_{3}\right)_{2} \times 4 \mathrm{H}_{2} \mathrm{O}\right.$, Merck), ethanol (Chimreactiv, p.a), chloromethylated styrene-6.7\% divinylbenzene copolymer (supplied by Purolite Victoria Romania), styrene-6.7\%divinylbenzene copolymer functionalized with phosphono-aminoacid groups $\left(\mathrm{G}_{\mathrm{F}}=\right.$ $0.492 \mathrm{mmoles}$ phosphono-aminoacid/g copolymer, synthesised in our laboratory) were used as starting materials for the photocatalytic polymer preparation. All other chemicals were used without further purification.

The FTIR spectrum was carried out using a Jasco FTIR spectrophotometer in the range $400-4000 \mathrm{~cm}^{-1}$, using $\mathrm{KBr}$ pellets and resolution of $4 \mathrm{~cm}^{-1}$. The UV-Vis diffuse reflectance spectrum of material was recorded by using a Varian Cary 100 UV-Vis spectrophotometer equipped with an integrating sphere. The band gap energy of the sample was calculated from the Kubelka-Munk transformed reflectance spectrum. Scanning electron microscopy (SEM) analysis was used a Quanta FEG 250 Microscope.

Thermal properties of the phosphono-aminoacid-Cd pendant groups grafted on macromolecular substrates was characterized through thermogravimetric analysis (TGA) and differential thermal analysis (DTA) using a TGA/SDTA 851-LF1100-Mettler apparatus at a heating rate of $10^{\circ} \mathrm{C} /$ min under air and nitrogen atmosphere and temperature in the range $25-900^{\circ} \mathrm{C}$.

The photocatalysis was developed in a PhotoLAB B400700 Basic Batch-L photoreactor provided by PeschlUltraviolet $\mathrm{GmbH}$, equipped with a submerged lamp (150 W Hg medium pressure, TQ150 type) that emits light in both ultraviolet and visible domain.

Synthesis of phosphono-aminoacid-Cd(II) pendant groups grafted onto styrene-6.7\%divinylbenzene copolymer

Four grams of phosphono-aminoacid pendant groups grafted onto styrene-6.7\%divinylbenzene copolymer (see Figure 1, Code: MP-AmAcid), GF $=0.492 \mathrm{mmoles}$ phosphono-aminoacid/g copolymer) and ethanol ( $25 \mathrm{~mL})$ was left for $24 \mathrm{~h}$ to allow the copolymer beads to swell. Immobilization of the metal was carried out by

*email: apopa_ro@yahoo.com, apopa@acad-icht.edu.tm.ro 
impregnation of the polymer support functionalized with phosphono-aminoacid groups with an aqueous solution of $\mathrm{Cd}\left(\mathrm{NO}_{3}\right)_{2} \times 4 \mathrm{H}_{2} \mathrm{O}$. This solution was prepared with 0.303 grams of $\mathrm{Cd}\left(\mathrm{NO}_{3}\right)_{2} \times 4 \mathrm{H}_{2} \mathrm{O}$ dissolved in $25 \mathrm{~mL}$ bidistilled water. The molar ratio of phosphono-aminoacid pendant groups functionalized on the copolymer: $\mathrm{Cd}\left(\mathrm{NO}_{3}\right)_{2} \times 4 \mathrm{H}_{2} \mathrm{O}$ was calculated to be 2:1. The pH of the sample was adjusted to 10 by using a solution of $1 \mathrm{M} \mathrm{NaOH}$. The sample was heated at $30^{\circ} \mathrm{C}$ and agitated by ultra-sound for 16 hours. Then after cooling the impregnated beads (phosphono-aminoacid-Cd(II) pendant groups grafted onto styrene-6.7\%divinylbenzene copolymer (Code: AmAcid Cd)) were separated by filtration, washed with ethanol and dried at $50^{\circ} \mathrm{C}$ for $24 \mathrm{~h}$.

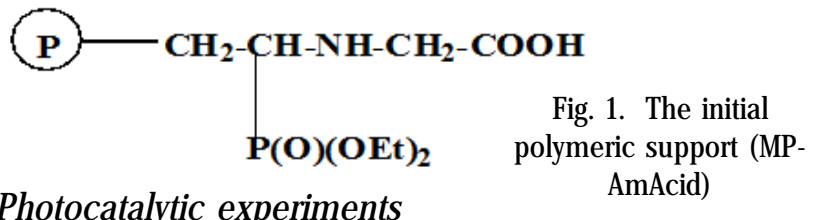

The photocatalytic performance of the impregnated beads with Cd(II) (Code: AmAcidCd) was tested for the heterogeneous oxidation of Congo Red azo dye. $700 \mathrm{~mL}$ of $100 \mathrm{mg} / \mathrm{L}$ Congo Red solution was mixed with $0.7 \mathrm{~g}$ of the catalyst for $30 \mathrm{~min}$ in the dark in order to achieve equilibrium. Then the UV lamp was switched on. Samples were collected at defined time intervals and filtered through a Millipore syringe filter ( $45 \mu \mathrm{m}$ pore size). The concentration of Congo Red solutions was analyzed at an absorbance value of $498 \mathrm{~nm}$. The UV-Vis spectra of Congo Red solutions were recorded by using a Varian Cary 100 UV-Vis spectrophotometer.

\section{Results and discussions}

Characterization of the phosphono-aminoacid-Cd(II) pendant groups grafted onto styrene-6.7\%-divinylbenzene copolymer (AmAcidCd)

Fourier transform infrared spectroscopy analysis

FTIR spectrum of AmAcidCd was recorded in the range 400-4000 using $\mathrm{KBr}$ pellet and it is presented in Figure 2.

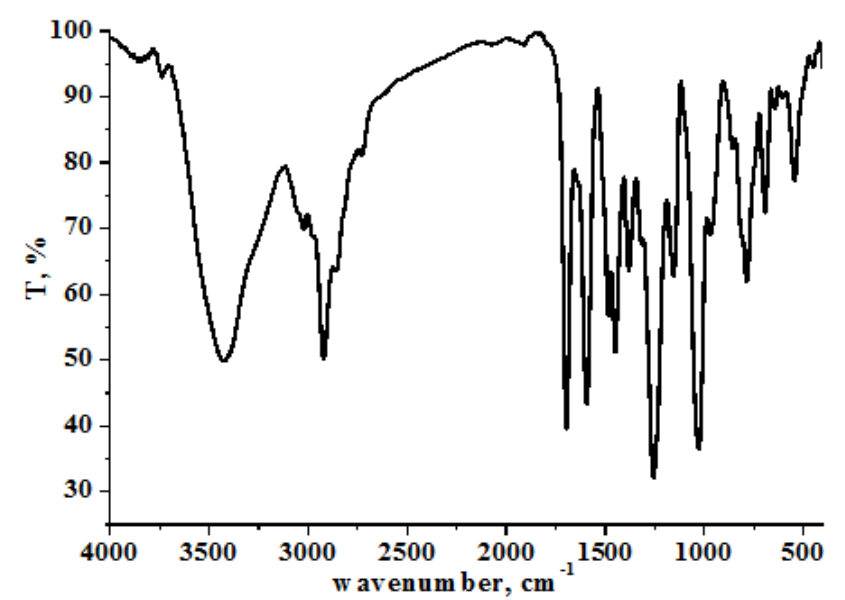

Fig. 2. FT-IR spectra of AmAcidCd

In the spectrum is presented an intense band at 3420 $\mathrm{cm}^{-1}$ and it was assigned to the $-\mathrm{OH}$ and $-\mathrm{NH}$ groups. The bands observed at about $2920 \mathrm{~cm}^{-1}$ could be assigned to the $-\mathrm{CH}$ stretching vibrations. The -NH group gave two bands: a band at $1690 \mathrm{~cm}^{-1}$ and a band at $1480 \mathrm{~cm}^{-1}$, respectively. The presence of the bands from $1590 \mathrm{~cm}^{-1}$ and $785 \mathrm{~cm}^{-1}$ are assigned to $\mathrm{C}=\mathrm{C}$ bond from aromatic ring. The absorption bands at 1257 and $1026 \mathrm{~cm}^{-1}$ associated with aliphatic P-O-C stretching and with stretching vibration of $\mathrm{P}=0$ group confirm the presence of phosphonate groups, as previously described [11].

\section{Termogravimetric analysis}

From the TG diagram of AmAcidCd, a small weight loss associated with the temperature range of $50-100^{\circ} \mathrm{C}$ is observed (Figure 3), which is attributable to evaporation of the water from humidity of the sample instant mass loss due to organic residues is observed on the TG curve. The next weight loss occurs in the range of $230-330^{\circ} \mathrm{C}$, being $51.98 \%$. It is attributed to an endothermic thermal decomposition effect with the elimination of gaseous compounds. The degradation of the remainder of the organic phase begins at about $350^{\circ} \mathrm{C}$, and at the end of the

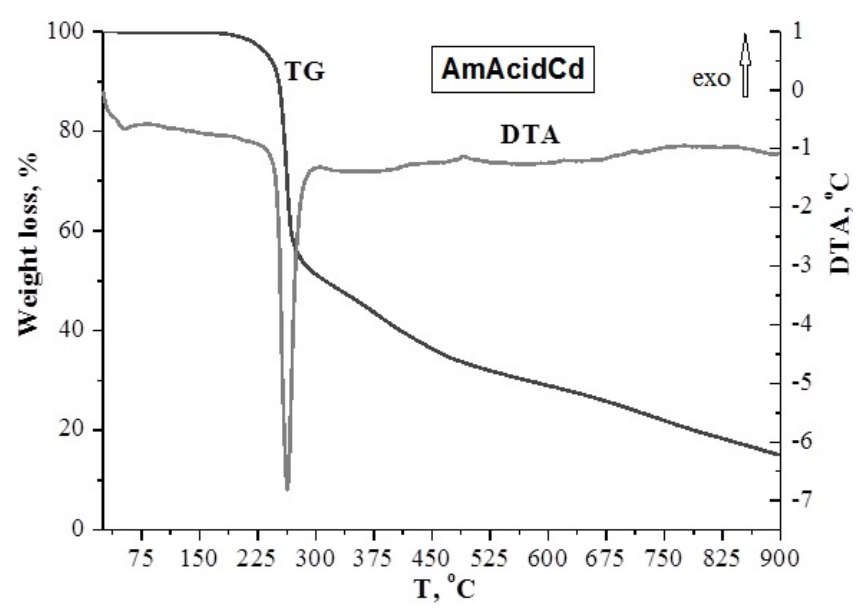

Fig. 3. TG/DTA curves of AmAcidCd sample in nitrogen atmosphere determination $\left(900{ }^{\circ} \mathrm{C}\right.$ ) the mass fall is $84.93 \%$.

From TG / DTA curve of AmAcidCd in air atmosphere (Figure 4), an endothermic effect is observed in the range $25-75^{\circ} \mathrm{C}$ due to water loss in the sample. Then there is a sequence of exothermic effects in the range $180-700^{\circ} \mathrm{C}$ due to the oxidative degradation of the AmAcidCd sample. At $358{ }^{\circ} \mathrm{C}, \mathrm{P}_{2} \mathrm{O}_{5}$ is also eliminated [12]. The total mass loss is $98.25 \%$. The final residue of $1.75 \%$ corresponds to the $\mathrm{CdO}$ that is formed [13]. From the final residue value of $\mathrm{CdO}$ was determined the yield of cadmium impregnation on polymeric support as $55.55 \%$.

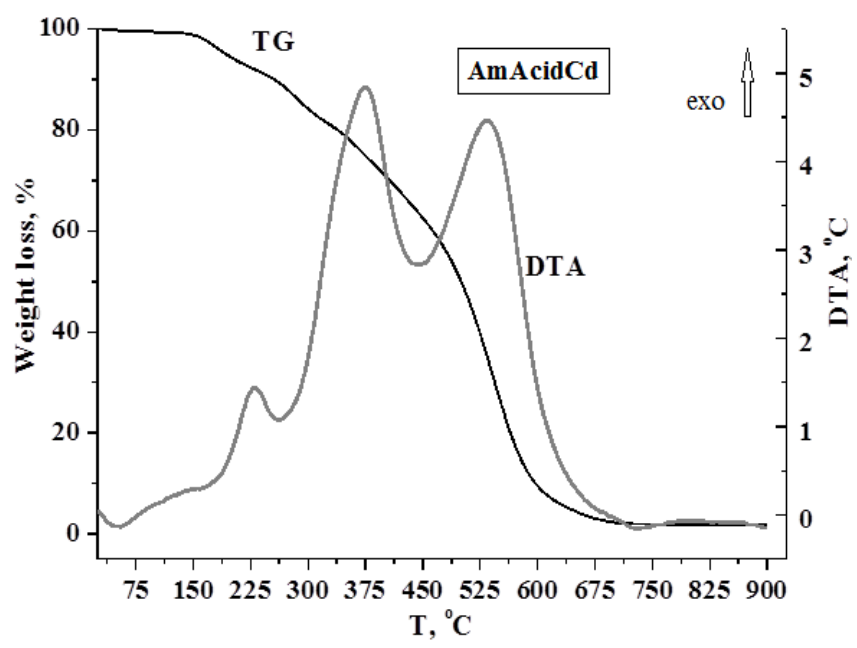

Fig. 4. TG/DTA curves of AmAcidCd sample in air atmosphere UV-Vis analysis

The UV-Vis diffuse reflectance spectrum of AmAcidCd sample (fig. 5) presents a broad absorption band in UV region, with two shoulders at $260 \mathrm{~nm}$ and $315 \mathrm{~nm}$, due to $\pi \rightarrow \pi^{*}$ transitions in phosphonate anion and divinylbenzene, respectively [14, 15]. Consequently, the band gap energies 


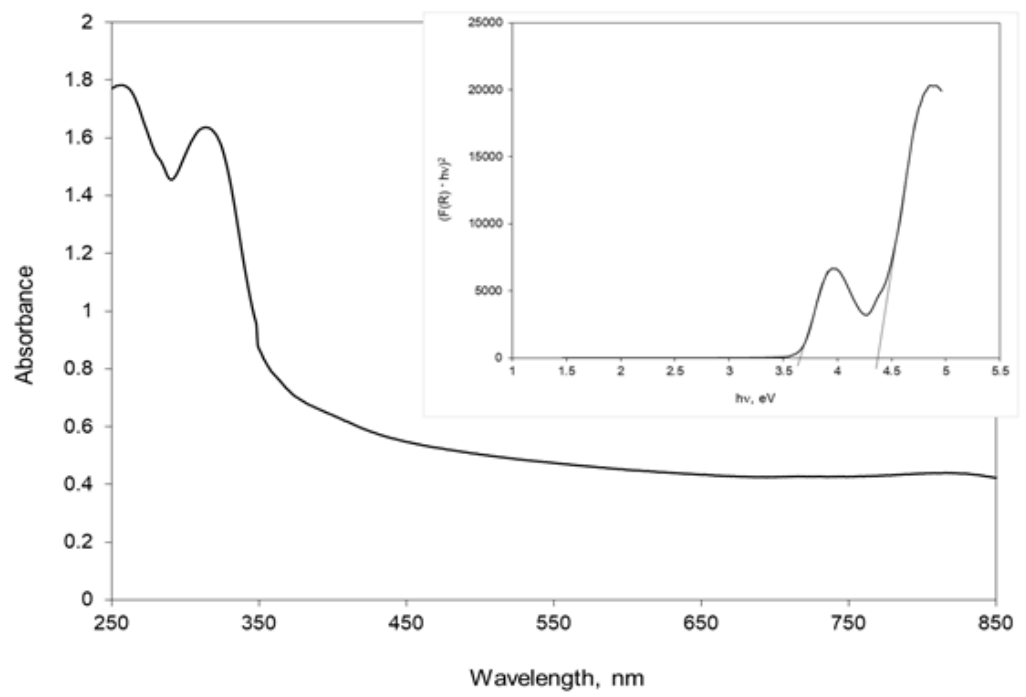

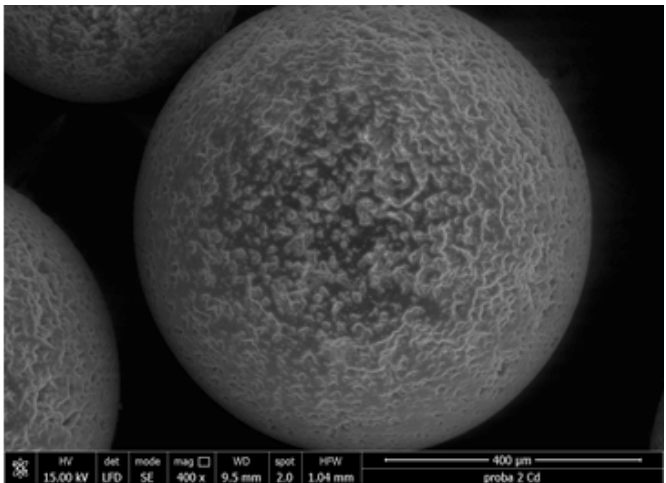

Fig. 6. SEM image of AmAcidCd

Fig. 5. UV-Vis diffuse reflectance spectrum of material. Inset: Kubelka-Munk

transformed reflectance spectrum

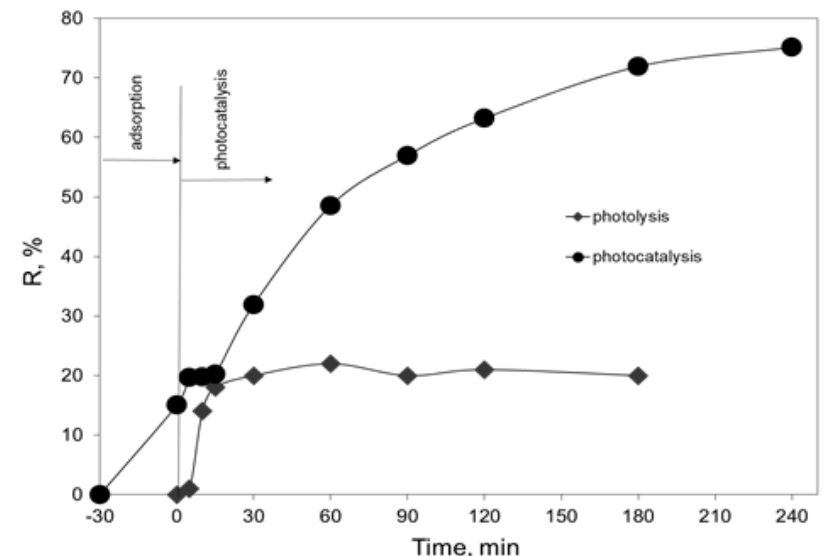

Fig. 7. The efficiency of Congo Red dye degradation on photolysis and photocatalysis

values determined from the dependence $(F(R) \cdot h v)^{2}-h v$ (presented in the inset of Figure 5) are: $\mathrm{E}_{\mathrm{g} 1}=4.4 \mathrm{eV} ; \mathrm{E}_{\mathrm{q}}=$ 3.6 eV. These values are similar to those obtained in the literature for various macromolecular compounds containing vinyl groups in the molecule $[15,16]$.

The morphology of impregnated beads with $\mathrm{Cd}(\mathrm{II})$ (Code: AmAcidCd) can be directly visualized by SEM micrograph in Figure 6 . The studied photocatalyst is presented under uniform spherical balls showing a network of micro cracks on its surface.

Photo-catalytic degradation of Congo Red dye

Figure 7 presents the efficiency of Congo Red degradation along the photolysis and photocatalysis processes. By irradiating the Congo Red solution without catalyst, a maximum efficiency of $21.0 \%$ was obtained, so that the presence of a photocatalyst in order to enhance the process is needed. After 30 min of dark adsorption 15.0 $\%$ of dye was retained by the catalyst, while after 240 minutes of photocatalysis, $75.1 \%$ of Congo Red was removed from the solution.

The experimental data were processed by using the Langmuir-Hinshelwood kinetic model [17], equation (1):

$$
r=\frac{-d C}{d t}=\frac{k K C}{1+K C}
$$

The Langmuir-Hinshelwood equation can be simplified to a pseudo-first order equation (2):

$$
\ln \left(\frac{C}{C_{0}}\right)=-k K t=-k_{a p p} t
$$

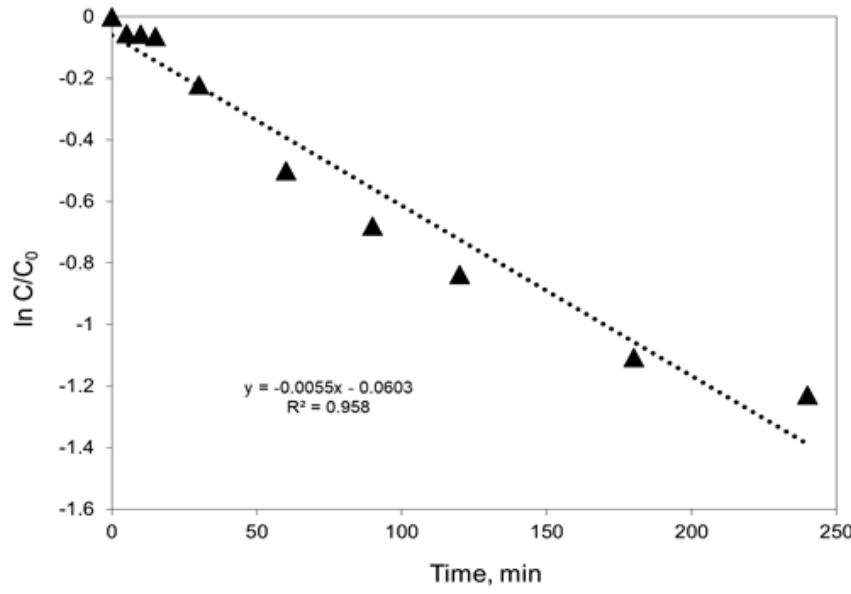

Fig. 8. Pseudo-first order kinetic model of Congo Red photocatalysis

where: $r$ is the rate of dye degradation, $C_{0}$ is the initial dye concentration $(\mathrm{mg} / \mathrm{L}), C$ is the concentration of the dye at any time $\mathrm{t}(\mathrm{mg} / \mathrm{L})$, tis the irradiation time $(\mathrm{min}), \mathrm{k}$ is the reaction rate constant $\left(\mathrm{min}^{-1}\right), \mathrm{K}$ is the Langmuir equilibrium constant $(\mathrm{L} / \mathrm{mg})$ and $\mathrm{k}_{\text {app }}$ is the apparent rate constant $\left(\mathrm{min}^{-1}\right)$.

Figure 8 presents the pseudo-first order kinetic model of Congo Red photocatalysis. The value of $k_{\text {apo }}$ apparent rate constant is $5.5 \cdot 10^{-3} \mathrm{~min}^{-1}$. This value is comparable with $\mathrm{k}_{\text {app }}$ reported by literature for other materials utilized as phofocatalysts, proving that the material can be successful utilized in the photocatalytic degradation of Congo Red [2 - 4].

\section{Conclusions}

The phosphono-aminoacid-Cd(II) pendant groups grafted on a polymeric support was synthetized and characterized with FTIR, TG/DTA, SEM and UV-Vis DRS techniques. The phosphonate group is present in the structure of the material and the yield of cadmium impregnation on polymeric supportwas found to be $55.6 \%$. The material was utilized for decontamination of water polluted with Congo Red dye. The results suggest that this compound might be used as photocatalyst under UV-Vis lightirradiation. The photocatalysis reaction obeys pseudofirst order kinetic model.

Acknowledgments: This work was supported partially by Program number 2, from the Institute of Chemistry Coriolan Dragulescu and by a grant of the Romanian National Authority for Scientific Research, CNCS -UEFISCDI, project number PN-III-P1-1.1- TE-2016-2008.

http://www.revistadechimie.ro 


\section{References}

1. ERDEMOGLU, S., AKSU, S.K., SAYILKAN, F., IZGI, B., ASILTURK, M., SAYILKAN, H., FRIMMEL, F., GUCER, S., J. Hazard. Mater., 155, 2008, p.469.

2. GÜY, N., ÇAKAR, S., ÖZACAR, M., J. Colloid Interf. Sci., 466, 2016, p.128.

3. J O, W.K., KUMAR, S., ISAACS, M.A., LEE, A.F., KARTHIKEYAN, S., Appl. Catal. B- Environ., 201, 2017, p.159.

4. ONG, C.B., MOHAMMAD, A.W., ROHANI, R., BA-ABBAD, M.M., HAIROM, N.H.H., Process Saf. Environ., 104, 2016, p.549.

5. VIDYA, C., MANJ UNATHA, C., CHANDRAPRABHA, M.N., RAJ SHEKAR, M., RAJ, A.M.A.L, J. Environ. Chem. Eng., 5, 2017, p.3172.

6. LOBIUC, A., OLARU, S., HANCU, E.I., COSTICA, N., FORTUNA M.E., ZAMFIRACHE, M.M., CONSTANTINESCU, G., Rev.Chim.(Bucharest), 69, no. 7, 2018, p.1628.

7. LARION, M., MURESAN, E.I., RADU, C.D., SANDU, I., CEREMPEI, A., CIMPOESU, N., Rev.Chim. (Bucharest), 69, no. 1, 2018, p.228.

8. POPA, A., MUNTEAN, S.G., PASKA, O.M., ILIESCU, S., ILIA, G., ZHANG, Z., Polym. Bull., 66, 2011, p.419.

9. HORA, S.G., SIMU, G., BUGARIU, L., POPA, A., RAD, R., Mol. Cryst.
Liq. Cryst., 416, 2004, p.137.

10. MUNTEAN, S.G., TODEA, A., RADULESCU-GRAD, M.E., POPA, A., Pure Appl Chem., 86(11), 2014, p.1771.

11. ARDELEAN, R., DAVIDESCU, C.M., DRAGAN, E.S., POPA, A., MARCU, C., NEGREA, A., Rev.Chim.(Bucharest), 67, no. 11, 2016, p.2180. 12. POPA, A., ILIA, G., ILIESCU, S., PLESU, N., ENE, R., PARVULESCU, V., Polym. Bull., 76, 2019, p.139.

13. WOJ CIECHOWSKI, K.T., MALECKI, A. Termochim. Acta, 331, 1999, p.73.

14. COLODRERO, R.M.P., CABEZA, A., OLIVERA-PASTOR, P., CHOQUESILLO-LAZARTE, D., GARCIA-RUIZ, J. M., TURNER, A., ILIA, G., MARANESCU, B., PAPATHANASIOU, K.E., HIX, G.B., DEMADIS, K.D., ARANDA, M.A.G., Inorg. Chem., 50, 2011, p.11202.

15. KIM, R., YUN, H.-J., YI, M.H., SHIN, S.C., KWON, S.-K., KIM, Y.-H., B. Korean Chem. Soc., 33(2), 2012, p.420.

16. YOUSIF, E., ABDALLH, M., HASHIM, H., SALIH, N., SALIMON, J., ABDULLAH, B.M., WIN, Y.-F., Int. J. Ind. Chem.,4(1), 2013, 4. doi:10.1186/2228-5547-4-4

17. ASENJ O, N.G., SANTAMARIA, R., BLANCO, C.,GRANDA, M., ÁLVAREZ, P., MENENDEZ, R., Carbon, 55, 2013, p.62.

$\overline{\text { Manuscript received: } 7.02 .2019}$ 